\title{
Anti-adherent Molds Yield Hydraulic Concrete Samples Suitable for Assessments of Surface and Water Absorption
}

\author{
Ernesto Mora ${ }^{1}$, Erick Castellón ${ }^{2 *}$ \\ 1. Facultad de Ingeniería, Universidad de Costa Rica, San José 11501-2060, Costa Rica \\ 2. Escuela de Química and CICIMA Universidad de Costa Rica, San José 11501-2060, Costa Rica \\ E-mail: erick.castellon@ucr.ac.cr (Corresponding author)
}

Received: 30 June 2021; Accepted: 11 August 2021; Available online: 30 September 2021

\begin{abstract}
To assess several quality parameters of hydraulic concrete, cubic samples of this material are commonly assembled in engineering laboratories using molds. It is ubiquitous the use of cubic metallic molds of volume 125 $\mathrm{cm}^{3}$; these molds require the application of demolding substances (such as oils) on their surfaces to avoid the adhesion of the final hardened concrete sample to the molds. Despite this common practice suitable for evaluating mechanical traits of the materials, the use of a demolding agent spoils the concrete samples for the assessment of surface and water absorption parameters. To overcome this difficulty, we propose a new anti-adherent cubic mold that requires no demolding agent. The construction of the new mold based on anti-adherent polytetrafluoroethene (PTFE, Teflon ${ }^{\circledR}$ ) is described with its use. To assess the claimed advantages of the new anti-adherent molds in testing surface and water diffusion traits of concrete samples, experiments on water contact angles, rates of water absorption and drying were performed on concrete specimens obtained with the classic and the new PTFE molds. It was proved the advantage of the anti-adherent mold over common metallic molds. The use of an oil as demolding agent in the concrete samples assembled in metallic molds produced conspicuous differences of water contact angles and absorption in comparison to clean concrete samples produced with PTFE molds.
\end{abstract}

Keywords: Concrete; Anti-adherent molds; Contact angle; Water absorption rate.

\section{Introduction}

Because of its versatility, general availability, moldability and hardening properties, hydraulic concrete has various applications, and has become one of the most used construction materials [1-6].

Concrete materials are intrinsically heterogeneous Macroscopically, hardened concrete comprises three main components: concrete paste (hydraulic cement + water), fine aggregates and coarse aggregates; the concrete paste binds the fine and coarse aggregates [6-10]. The fine and coarse aggregates represent about $75 \%$ of the volume of the hydraulic concrete. Even though these aggregates can be viewed as dispersed inert materials in the concrete paste [8-12], they largely determine the properties of the fresh mixture and of the final hardened material [5,1315]. From a macroscopic perspective, concrete materials are considered composites formed of a hydrated crystalline matrix with fine and coarse aggregates embedded therein. From a microscopic or molecular point of view, the hydrated crystalline matrix is composed of several substances such as hydrated calcium silicates (Ca-Si$\mathrm{O}-\mathrm{H}$ networks) and calcium hydroxide. Each component of concrete has a role in establishing the physical and chemical properties of the composite material. These characteristics of concrete materials require rigorous quality assessments to warrant its suitability and durability [7,16,17].

Among the characteristics of concrete, hardness, porosity, surface and transport properties are highly relevant because of their implications for the mechanical stability and water permeability of concrete materials $[9,18,19]$. In the current practice of construction engineering, some concrete properties (parameters as quality indicators) are commonly evaluated based on small concrete samples (commonly small cubes, prisms, or cylinders) on which tests are performed $[9,16,20,21]$. The standard techniques to obtain the samples (for example, cubes of side $5 \mathrm{~cm}$ prepared in steel molds) are suitable for the assessment of their mechanical parameters. The use of steel molds typically requires an application of a demolding agent such as a mineral oil to avoid the samples adhering to the molds $[20,22,23]$. This demolding agent necessarily contacts the concrete samples, so altering their surfaces. If no demolding agent is used, the resulting concrete samples have a highly rough surface because of fragmentation of the material adhering to the molds.

The induction of hydrophobicity in concrete materials has become a current trend in construction engineering [24-27]. Hydrophobic concrete is a promising material through its repellency of water and minimum flow of water through the material, thereby bestowing an enhanced durability $[1,5,15,28,29]$. To assess the hydrophobicity and 
the decreased flow of water through the materials, two tests are crucial: water contact angle and rate of water absorption. These tests require a clean concrete sample with no demolding substance that contaminates its surface. Also, assessment of the water contact angle requires a clean flat surface, unsuitable with conventional steel molds used without demolding agent.

To assess surface and water absorption traits of concrete materials, special molds are hence required. Here we report the construction and use of anti-adherent molds for hydraulic concrete assembled with polytetrafluoroethene (PTF, also known as the brand name Teflon). We emphasize the importance of these anti-adherent molds for concrete samples suitable for the assessment of their water contact angles and water absorption kinetics.

\section{Experiments}

\subsection{Construction of anti-adherent molds}

An anti-adherent mold for cubic concrete samples of edge $25 \mathrm{~mm}$ was built with sheets of polytetrafluoroethene (Teflon ${ }^{\circledR}$ ) of thickness $10 \mathrm{~mm}$ using precise mechanical techniques. Figure 1 shows the design details and photographs of an assembled mold and its parts.

A tamping stick of rectangular cross section $12.5 \mathrm{~mm} \times 6.25 \mathrm{~mm}$ was made to press the fresh concrete pastes during the molding. The designed mold allows a preparation of three cubic samples of concrete materials.
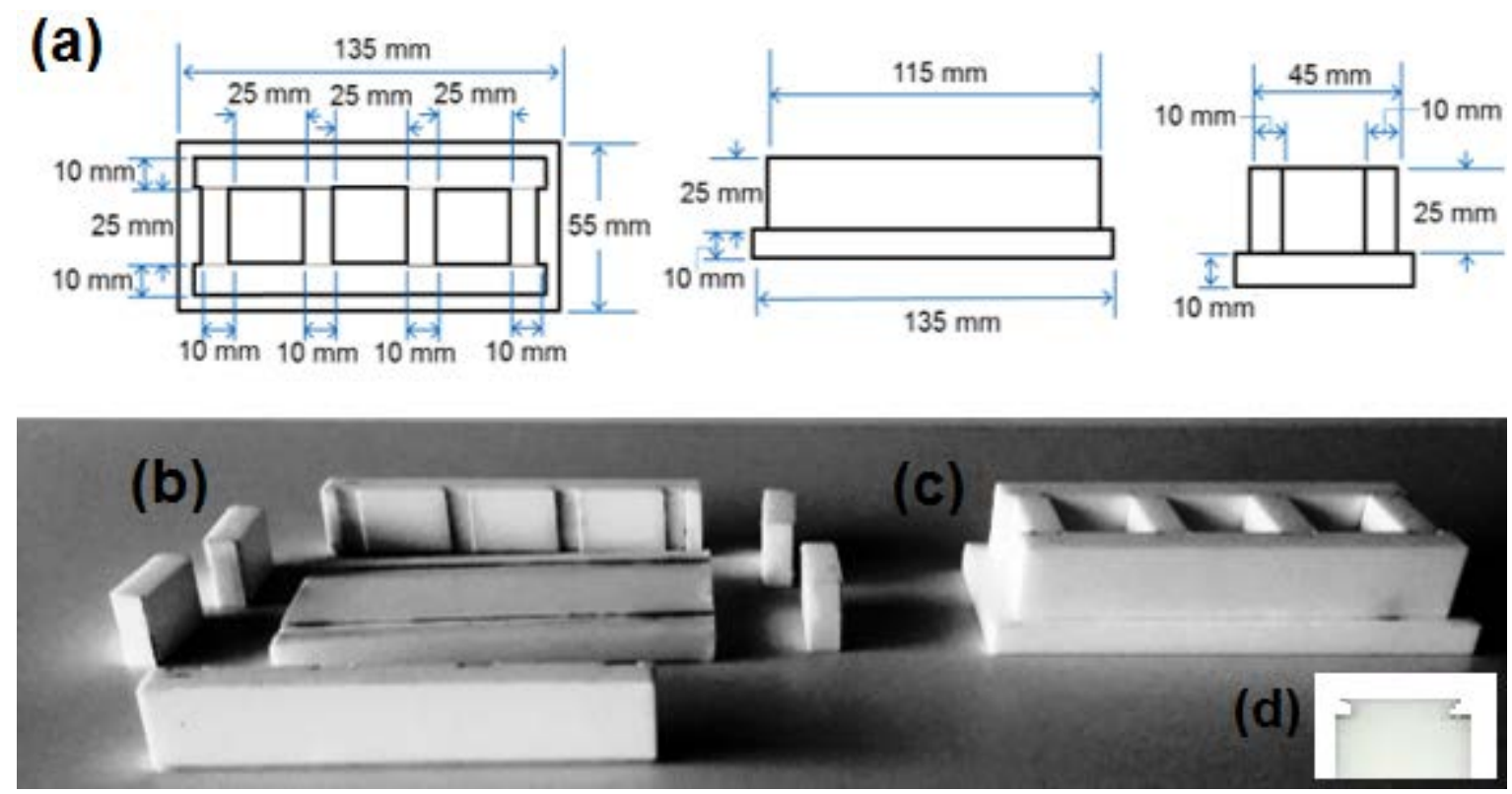

Figure 1. Anti-adherent molds made with polytetrafluoroethene (PTFE, Teflon). The several parts of this mold were designed to be assembled and disassembled on sliding through "dovetail” joints. (a) Mold design and dimensions. (b) Pieces that comprise the PTFE mold. (c) Assembled mold. (d) “Dovetail” joint.

\subsection{Concrete formulation and molding}

Two different concrete pastes were prepared: common concrete paste and hydrophobized concrete paste. The common concrete paste was prepared by mixing cement, sand and water at mass proportions 1:2.68:0.49 respectively. The hydrophobized concrete paste was prepared with cement, sand, water and n-dodecylfunctionalized silica microparticles (C12-sil) at proportions 1:2.68:0.49:0.04 respectively [25]. Both pastes were molded in metallic molds and polytetrafluoroethene (PTFE) anti-adherent molds. A light oil (40WD $\left.{ }^{\circledR}\right)$ was used on the metallic mold surfaces to avoid adhesion of the hardened concrete samples. No demolding agent was used on the PTFE mold surfaces. The samples were allowed to harden in the molds for $24 \mathrm{~h}$. To avoid water evaporation, the samples in the mold were wrapped with plastic. After $24 \mathrm{~h}$ the samples were demolded on disassembly of the molds; the concrete samples were cured immersed in water for 28 days at $25{ }^{\circ} \mathrm{C}$ [20]. After curing, the samples were dried for 7 days at $25{ }^{\circ} \mathrm{C}$ in an environment with relative humidity $60 \%$. To observe the deleterious effect of the undesired adhesion between concrete and mold, other concrete samples were similarly prepared (without hydrophobic particles) and molded in a metallic mold without the aid of oil as demolding agent. Demolding operation of these latter samples was difficult and produced cracked concrete surfaces with high rugosity. 


\subsection{Measurements of water contact angle}

Drops of water were placed on the surface of the concrete specimens; images of the water drops were captured with a digital camera; the water contact angles were measured with the aid of software for digital analysis and processing (DropAnalysis plugin of ImageJ) [30]. The water affinity of a sample is classified according to the value of the water contact angle $\theta$ : for $\theta<90^{\circ}$ the material is considered hydrophilic, for $\theta>90^{\circ}$ the material is classified as hydrophobic. Superhydrophobic materials are those with angles $\theta>150^{\circ}$ [31].

\subsection{Rate of water absorption}

For these measurements, a weighed cubic sample of a concrete material was immersed in a carefully measured volume of water in a beaker. After several durations (time t) the water in contact with the concrete sample was poured into a finely graduated cylinder to measure the volume of the non-absorbed water. During the experiments, the beaker with the concrete and water remained tightly tapped to avoid water evaporation. From these measurements we calculated the relative water absorption A of the specimen:

$$
A=\frac{m_{\text {absorbed water }}}{m_{\text {specimen }}}
$$

\subsection{Drying kinetic}

After curing of the concrete samples -- immersed in water for 28 days, it was assessed the drying dynamics of these concrete specimens. Each sample was placed in an environment at $25{ }^{\circ} \mathrm{C}$ and relative humidity $60 \%$. The mass of the samples was registered periodically for 7 days. The mass loss of the samples is due to water evaporation (drying) caused by diffusion.

\subsection{Compressive strength tests}

The compressive strength of each concrete sample was measured according to the norm ASTM-C109 [20]. The only change introduced in this assessment was the one related to the size of the samples (cubes of side $25 \mathrm{~mm}$ instead of $50 \mathrm{~mm}$ ).

\section{Results and discussion}

The guiding idea behind the research reported in the present article is that surface and water diffusion traits of concrete materials could be affected by the presence of demolding agents which are necessary for molding concrete cubic samples in ubiquitous, normative metallic molds. For those cases in which it is necessary to assess surface and water diffusion properties it is proposed the use of molds built with an anti-adherent material (polytetrafluoroethene, PTFE).

The use of demolding agents with metallic molds is in fact encouraged to warrant a convenient demolding of the samples and the preservation of the metallic molds. The presence of demolding agents such as a light oil does not affect the mechanical traits of the concrete specimens assembled in metallic molds. In fact, it was verified that all the concrete samples prepared in metallic molds (with demolding oil) and in the proposed PTFE molds (without any demolding substance) showed no significant differences of the compressive strength values (maximum relative deviation with respect to the average was 7\%). This result also confirmed that molding can be properly made on the new anti-adherent molds proposed in this article.

A noticeable aspect of the proposed new mold is its decreased size (1/8 the volume of a standard cube $\left.125 \mathrm{~cm}^{3}\right)$; this decreased size allows the use of less concrete paste for the assembly of the samples. The assessments of water contact angle and water absorption do not require the use of massive samples; the use of small specimens facilitates the absorption measurement in small volumetric glassware.

Demolding of the concrete samples is straightforward on disassembly of the molds. This disassembly is simple because of the design and anti-adherent nature of the polytetrafluoroethene (PTFE) material. The disassembly of the mold is performed on sliding its parts through the "dovetail" joints. Each cubic sample releases from the mold with minimal effort.

The most important feature of this anti-adherent mold is that it permits obtaining clean samples of concrete materials suitable for surface and absorption assessments. The attempts to produce concrete material specimens in conventional steel molds without demolding substances such as a petroleum oil typically result in samples with cracked, broken and highly rough surfaces, as Figure 2 shows. In contrast, smooth clean surfaces result from molding with the anti-adherent PTFE mold (see Figure 2).

Measurements of water contact angle require the tests to be performed on planar smooth surfaces because rugosity affects the value of this contact angle (as the models of Wenzel or Cassie-Baxter predict) [32].

Smooth planar surfaces were obtained in steel molds using a demolding agent, but the demolding substances affected the chemistry of the concrete materials, spoiling those surfaces for surface tests. The use of steel molds 
must hence be deprecated for two mutually exclusive reasons: they produce smooth contaminated concrete materials, or they yield clean but rough and cracked surfaces on the concrete materials. The latter point was experimentally verified on preparing a concrete paste that was then molded in a steel mold with a demolding agent (petroleum oil) and in an anti-adherent PTFE mold.

In Figure 3 the use of a demolding agent (light petroleum oil in the present case) reveals a spoilt experiment because the water contact angle was modified by this substance.

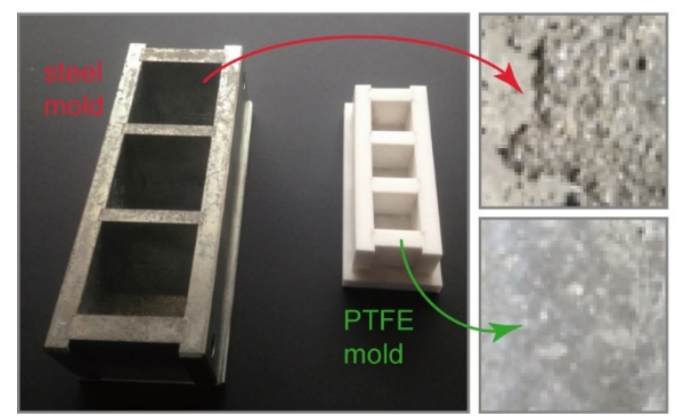

Figure 2. Surfaces of concrete samples produced in a steel mold (without demolding agent) and on an anti-adherent PTFE mold.
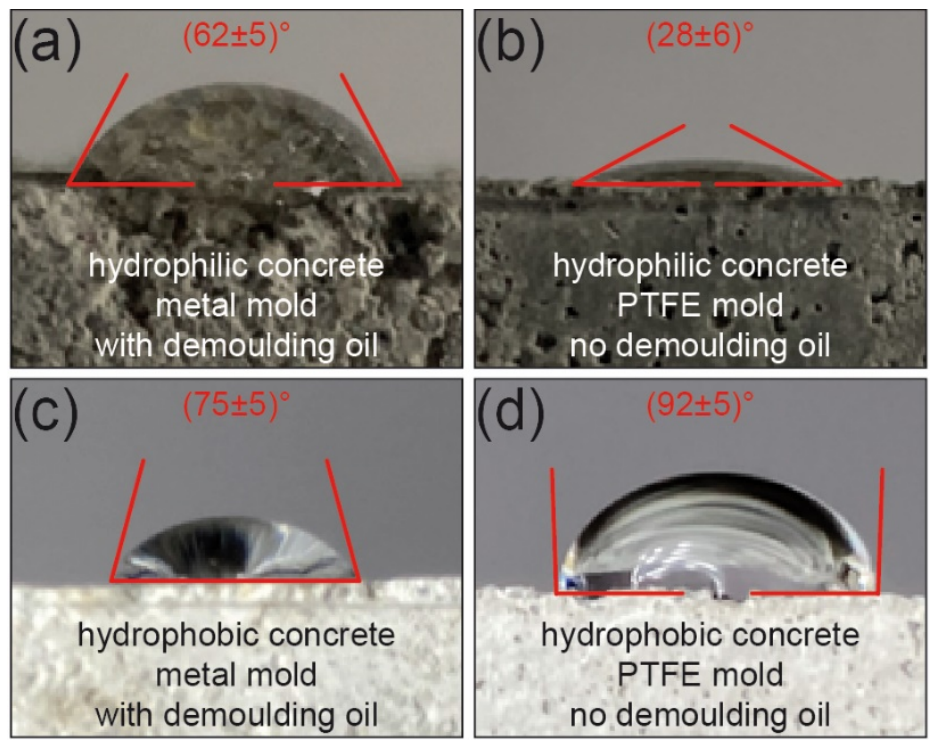

Figure 3. Water contact angles of cured concrete samples prepared with and without C12-sil hydrophobic particles. Samples were produced with the same formulated concrete paste but in separate molds. (a) Sample of hydrophilic concrete (without C12-sil particles) molded in a steel mold with a demolding agent. (b) Sample of hydrophilic concrete (without C12-sil particles) molded in an anti-adherent PTFE mold without a demolding agent. (c) Sample of hydrophobic concrete (with C12-sil particles) molded in a steel mold with a demolding agent. (d) Sample of hydrophobic concrete (with C12-sil particles) molded in an anti-adherent PTFE mold without a demolding agent. In each case the displayed value of water contact angle is the mean of six independent measurements (left and right sides) of three separate spots on the surfaces; the uncertainties are the standard deviations.

It is noticeable that the use of a demolding agent affects the assessment of the water contact angle. In the case of the hydrophilic concrete materials (Figure $3(\mathrm{a}, \mathrm{b})$ ), the demolding oil on the sample surface caused an increased value of the contact angle. The contrary trend is observed in the case of the hydrophobic concrete samples (Figure 3 (c, d)) --a decreased value of the contact angle is due to the demolding oil spread on the sample. Moreover, there is a coincident trend for the water contact angles of the concrete materials exposed to the demolding oil regardless of the chemical modifications imposed to the materials --(62 \pm 5$)^{\circ}$ and $(75 \pm 5)^{\circ}$ for hydrophilic and hydrophobic concrete samples respectively.

The water absorption of concrete is another relevant figure-of-merit regarding chemical modifications that affect surface and bulk permeability to water of these materials. To prove how a demolding agent affects the measurement of water absorption, samples similar to those used for measurement of the water contact angle were 
prepared in an anti-adherent mold and in a steel mold with a demolding petroleum oil spread on the mold surfaces. The rate of water absorption of these samples was measured; the results are displayed in Figure 4.

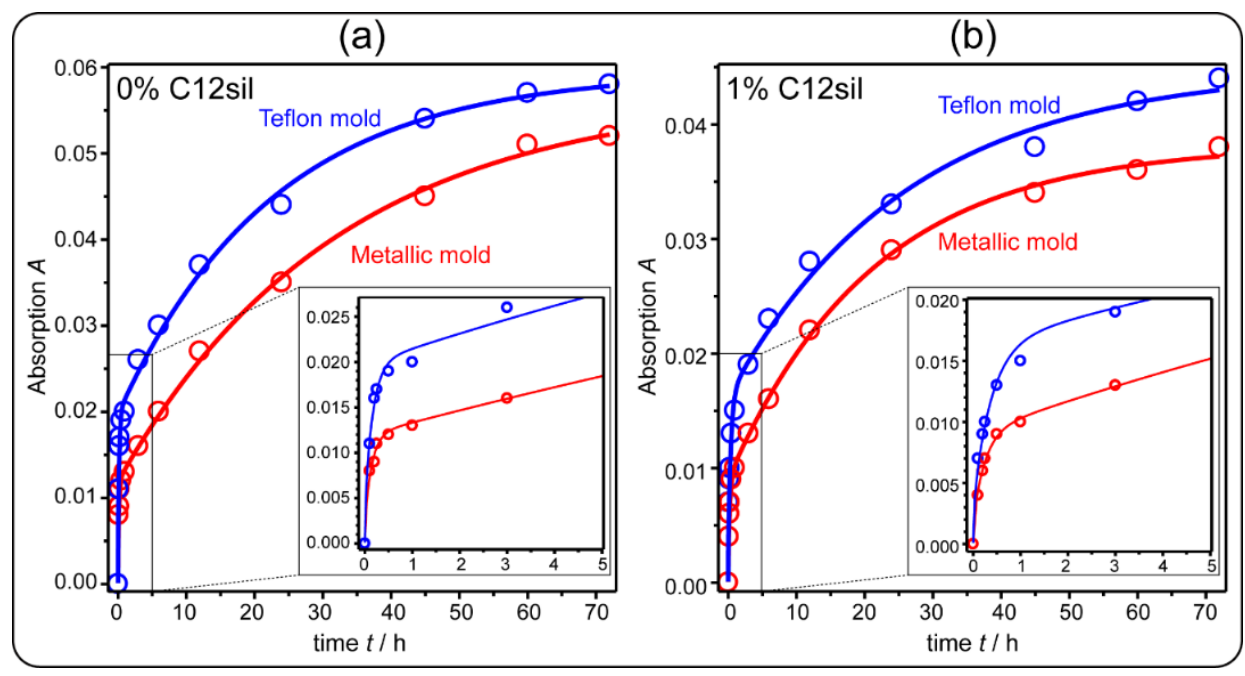

Figure 4. Water absorption dynamics of concrete cubic samples of side $25 \mathrm{~mm}$, with the same formulation ((a) 0\% C12sil, and (b) 1\% C12sil), but casted in Teflon molds (blue) and in metallic molds (red). The molding in the metallic molds required the use of an oil as demolding agent to avoid adhesion of the sample to the molds. Continuous lines represent the fits of experimental data with a function of absorption based on the Kibler-Carter model (Equation 2). Absorption A is dimensionless (quotient of mass of absorbed water and concrete sample mass). The inset shows the dynamics at the beginning of the absorption processes.

Despite each pair of samples have been prepared with concrete pastes of equal compositions (hydrophilic and hydrophobic concretes in Figure 4 (a) and (b) respectively), each pair of specimens show different dynamics of water absorption, as is evident from the graphs in Figure 4 and from the fitted parameters of the mathematical model of Kibler-Carter for water absorption [25],

$$
A(t)=A_{\infty}\left\{1-\frac{8}{\pi^{2}} \sum_{j=0}^{\infty} \frac{r_{1} e^{-r_{2} t}-r_{2} e^{-r_{1} t}}{(2 j+1)\left(r_{1}-r_{2}\right)}+\frac{8}{\pi^{2}}\left(\frac{k \beta}{\gamma+\beta}\right) \sum_{j=0}^{\infty} \frac{e^{-r_{2} t}-e^{-r_{1} t}}{r_{1}-r_{2}}\right\}
$$

in which,

$$
\begin{aligned}
& r_{1}=\frac{1}{2}\left[\left\{(2 j+1)^{2} k+\gamma+\beta\right\}+\sqrt{\left\{(2 j+1)^{2} k+\gamma+\beta\right\}^{2}-4 k \beta(2 j+1)^{2}}\right] \\
& r_{2}=\frac{1}{2}\left[\left\{(2 j+1)^{2} k+\gamma+\beta\right\}-\sqrt{\left\{(2 j+1)^{2} k+\gamma+\beta\right\}^{2}-4 k \beta(2 j+1)^{2}}\right]
\end{aligned}
$$

where $A$, represents the relative absorption as function of time $t$. This model considers that, as the water molecules diffuse inside the materials, they exist as free or bound molecules. The parameters $\gamma$ and $\beta$ represent specific rates for the interconversion of free to bound water inside the materials and vice versa; $A_{\infty}$ is the relative absorption at infinite time and $k$ is a first-order specific diffusion rate. The fitted parameters appear in Table 1.

Table 1. Fitted parameters of Equation 2 obtained on modeling the experimental data of water absorption of concrete samples prepared in Teflon and metal molds.

\begin{tabular}{lcccc}
\hline Sample & $A_{\infty}$ & $k / h^{-1}$ & $\beta / h^{-1}$ & $\gamma / h^{-1}$ \\
\hline $\begin{array}{l}\text { 0\% C12sil } \\
\text { Metallic mold (with oil) } \\
\text { 0\% C12sil }\end{array}$ & $0.057 \pm 0.001$ & $7 \pm 1$ & $0.031 \pm 0.002$ & $0.12 \pm 0.01$ \\
$\begin{array}{l}\text { Teflon mold (without oil) } \\
\text { 1\% C12sil }\end{array}$ & $0.059 \pm 0.001$ & $6 \pm 1$ & $0.045 \pm 0.004$ & $0.09 \pm 0.01$ \\
$\begin{array}{l}\text { Metallic mold (with oil) } \\
\begin{array}{l}\text { \% C12sil } \\
\text { Teflon mold (without oil) }\end{array}\end{array}$ & $0.0382 \pm 0.0005$ & $3.8 \pm 0.6$ & $0.048 \pm 0.003$ & $0.14 \pm 0.01$ \\
\hline
\end{tabular}


From Figure 4 and Table 1 it is noticeable that the presence of the demolding agent affects the water absorption dynamics. From the beginning of the experiments (see insets in Figure 4), conspicuous gaps among the curves become evident. In both cases, the presence of demolding oil (in the materials prepared with metallic molds) produces an apparent decrease of the water diffusion rate through the samples; as well as a diminishing of the maximum relative water absorption values ( $A_{\infty}$ in Table 1$)$. A diminished transit of water through concrete materials is desirable in many cases. Therefore, the use of demolding agents in preparing concrete samples lead to false positive results. This apparently improved condition is not permanent as the demolding agent could evaporate or degrade. Real permanent improvements of concrete are more conveniently brought about through chemical modifications of the concrete matrix [25].

Water transport experiments of drying kinetics were also assessed to evaluate the effect of using demolding oil in preparing concrete samples. In these experiments, the water diffusion occurs in the contrary direction than that of the absorption experiments.

As the demolding agent could be present in the concrete surface, it could affect the drying rate of the materials. Figure 5 display the drying curves of pairs of concrete samples prepared with equal compositions but in different molds (metallic mold with demolding oil and anti-adherent mold without any demolding agent). The data of mass sample $m$ as function of time $t$ were fitted with a stretched exponential decay equation:

$$
m=m_{0}+\left(m_{\infty}-m_{0}\right)\left(1-\exp \left(-(\alpha t)^{\delta}\right)\right)
$$

in which $m_{0}$ is the initial mass of fully water saturated concrete samples (after 28 days of curing immersed in water), $m_{\infty}$ is the extrapolated mass of the completely dried samples, $\alpha$ is a specific rate of drying, and $\delta$ is a stretching factor. The value of $\delta=0.45$ was found to fit well all the data sets, allowing to directly compare the adjusted specific rates $\alpha$, which is the most important of the fitted parameters. The initial and final masses greatly depend upon the specific dimensions of the molds, as little variations of the dimensions could lead to large fluctuations of the sample masses. It was found that the specific drying rates were practically unaffected by the presence of a demolding agent. This finding can be explained by the fact that the light oil used as demolding substance is as the water also volatile. However, this volatility depends upon the substances used as demolding agents, and therefore the specific rate of drying could change accordingly.

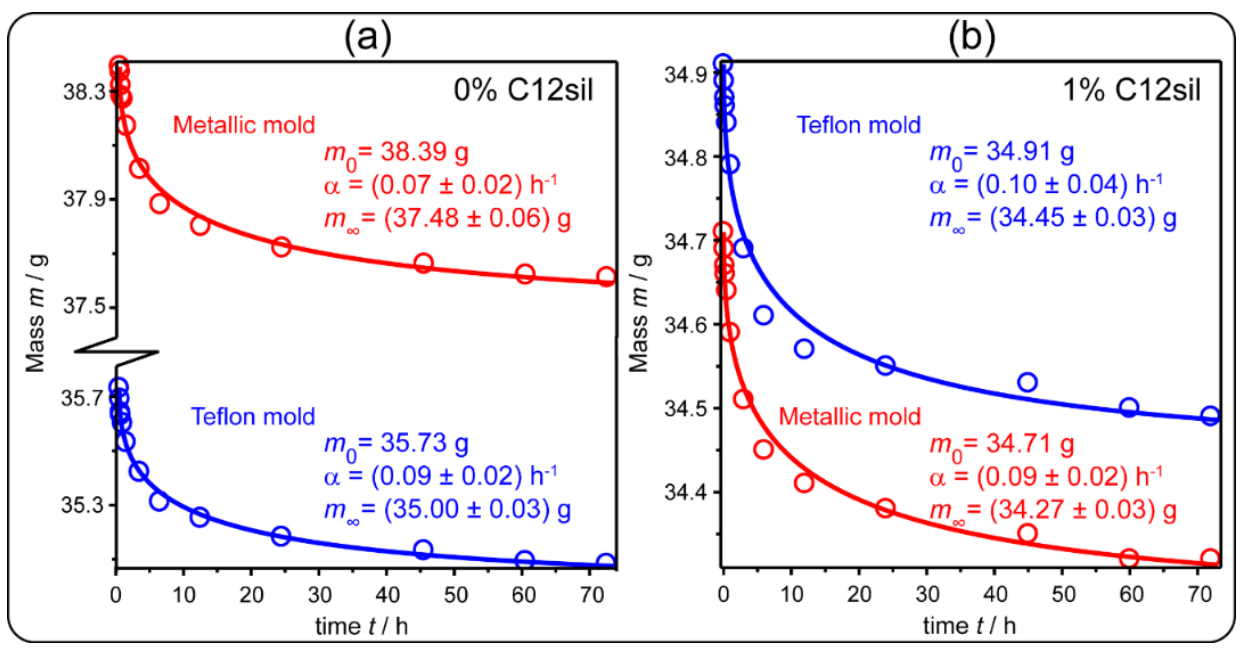

Figure 5. Drying dynamics of concrete samples with the same formulation ((a) 0\% C12sil, and (b) 1\% C12sil), but casted with the aid of a demolding oil (in a metallic cubic mold, red) and without any demolding agent (prepared in a Teflon cubic mold, blue). The red and blue lines represent the fits of experimental data with model function in Equation 3, with $\delta=0.45$.

Regarding the maintenance of the PTFE anti-adherent molds, they were successfully cleaned with a soft brush and water. About their durability, it was found that after 50 cycles of molding and demolding, the resulting internal surfaces of the mold were in good condition, with minimal scratches. PTFE is worldwide traded under the commercial name Teflon ${ }^{\circledR}$. This polymeric material could be purchased as sheets of thickness $1 \mathrm{~cm}$ which are convenient for constructing the proposed molds. The price of the abovementioned PTFE sheets is about 100 USD per square meter, being this surface enough for constructing up to 5 molds with 3 cubic pots each, making the material economically affordable. The construction process should be made in a precise mechanical workshop with a milling machine. 


\section{Conclusion}

The use of demolding agents such as a light oil is necessary to assembly concrete samples in metallic molds to prevent adhesion of the concrete samples to the molds. Despite this usage of a demolding substance does not affect mechanical assessments of the concrete materials, it was proved in the present research that these substances modify important surface and diffusion traits: water contact angle and absorption dynamics. To overcome this inconvenient alteration in concrete material samples, it is proposed the construction of molds based on polytetrafluoroethene (PTFE). The anti-adherent nature of PTFE makes suitable the molding of concrete cubic samples without the aid of any demolding substance that could spoil the samples for surface and diffusion assessments. Another significant trait of the proposed molds is the reduced size of the cubic samples (side $25 \mathrm{~mm}$ ), allowing the assembly of specimens with less precursor materials in laboratory tests. The simple design of the proposed molds, their reusability, as well as the high availability of PTFE material, make of the PTFE molds a convenient, affordable option for molding concrete samples in engineering laboratories.

\section{Acknowledgement}

This work was partly supported by Vicerrectoría de Investigación de la Universidad de Costa Rica (UCR).

\section{References}

[1] McCormac J, Brown R. Design of Reinforced Concrete. Wiley, New Jersey, USA. 2013.

[2] Surahyo A. Concrete Construction. Springer, Cham, Switzerland. 2019.

[3] Yu S, Xia M, Sanjayan J, Yang L, Xiao L, Du H. Microstructural characterization of 3D printed concrete. Journal of Building Engineering. 2021; 44: 1-8. DOI: doi.org/10.1016/j.jobe.2021.102948

[4] Neville A. Concrete Technology. Pearson, Harlow, UK. 2010.

[5] Chess P, Green W. Durability of reinforced concrete structures. CRC Press, Boca Raton Florida, USA. 2020.

[6] Yang W. The Issues and Discussion of Modern Concrete Science. Springer, Berlin, Germany. 2015.

[7] Berry B, Green W. Corrosion and Protection of Reinforced Concrete. CRC Press, Boca Raton Florida, USA. 2021.

[8] Li Z. Advanced Concrete Technology. Wiley, New Jersey, USA. 2011.

[9] Kosmatka S, Wilson M. Design and Control of Concrete Mixtures. PCA, Skokie Illinois, USA. 2016.

[10] Dvorkin L, Zhitkovsky V, Lushnikova N, Rivakov Y. Metakaolin and Fly Ash as Mineral Admixtures for Concrete. CRC Press, Boca Raton Florida, USA. 2021.

[11] Wong H, Barakat R, Alhilali A, Saleh M, Cheeseman C. Hydrophobic concrete using waste paper sludge ash. Cement Concrete Research. 2015; 70: 9-20. DOI: 10.1016/j.cemconres.2015.01.005

[12] Nawy E. Concrete Construction Engineering. CRC Press, Boca Raton Florida, USA. 2008.

[13] Aitcin P. Science and Technology of Concrete. Admixtures, Woodhead Publishing, London, UK. 2016.

[14] Kurdowski W. Cement and Concrete Chemistry. Springer, Berlin, Germany. 2014.

[15] Mindess S. Developments in the formulation and reinforcement of concrete. Elsevier, Kidlington, UK. 2019.

[16] Hewlett P, Liska M. Lea’s Chemistry Cement and Concrete. Elsevier, Kidlington, UK. 2019.

[17] Coffetti D, Crotti E, Gazzaniga G, Gottardo R, Pastore T, Coppola L. Protection of Concrete Structures: Performance Analysis of Different Commercial Products and System. Materials. 2021; 14: 1-15. DOI: doi.org/10.3390/ma14133719

[18] Tokyay M. Cement and Concrete Mineral Admixtures. CRC Press, Boca Raton Florida, USA. 2008.

[19] Chaubey A. Practical Concrete Mix Design. CRC Press, Boca Raton Florida, USA. 2020.

[20] ASTM C109/C109M Standard Test Method for Compressive Strength of Hydraulic Cement Mortars (Using 2-in. or [50-mm] Cube Specimens). ASTM International, West Conshohocken PA, USA. 2020.

[21] ASTM C31/C31M Standard Practice for Making and Curing Concrete Test Specimens in the Field. ASTM International, West Conshohocken PA, USA. 2021.

[22] Megid W, Khayat K. Variations in surface quality of self-consolidation and highly workable concretes with formwork material. Construction and Building Materials. 2020; 238: 1-12. DOI: doi.org/10.1016/j. conbuildmat.2019.117638

[23] Savukaitis G, Daukšys M, Juočiūnas S, Grinys A, Kriptavičius D. The influence of new and used form work coated with different release agents on the appearance of the formed concrete surface. Journal of Building Engineering. 2021; 42: 1-14. DOI: doi.org/10.1016/j.jobe.2021.102807

[24] Al-Kheetan M, Rahman M, Chamberlain D. Development of hydrophobic concrete by adding dual-crystalline admixture at mixing stage. Structural Concrete. 2018; 19: 1504-1511. DOI: 10.1002/suco.201700254 
[25] Mora E, González G, Romero P, Castellón E. Control of water absorption in concrete materials by modification with hybrid hydrophobic silica particles. Construction and Building Materials. 2019; 221: 210 218. DOI:https://doi.org/10.1016/j.conbuildmat.2019.06.086

[26] Ramachandran R, Kozhukhova M, Sobolev K, Nosonovsky M. Anti-Icing Superhydrophobic Surfaces: Controlling Entropic Molecular Interactions to Design Novel Icephobic Concrete. Entropy. 2016; 18 (132): 1-27. DOI:10.3390/e18040132

[27] Zhang P, Li P, Fan H, Shang H, Guo S, Zhao T. Carbonation of Water Repellent-Treated Concrete. Advances in Materials Science and Engineering. 2017: 1-8. DOI: https://doi.org/10.1155/2017/1343947

[28] Bissonnette B, Courard L, Garbanacz A. Concrete surface engineering. CRC Press, Boca Raton Florida, USA. 2016.

[29] Metha K, Monteiro P. Concrete. McGraw-Hill, New York, USA. 2006.

[30] Stalder A, Kulik G, Sage D, Barbieri L, Hoffmann P. A snake-based approach to accurate determination of both contact points and contact angles. Colloid. Surface. 2006; 286: 92-103. DOI:10.1016/j.colsurfa. 2006.03.008

[31] Liu M, Luo Y, Jia D. Synthesis of mechanically durable superhydrophobic polymer materials with roughnessregeneration performance. Composites Part A 133. 2020: 1-8. DOI: 10.1016/j.compositesa.2020.105861

[32] Butt H, Graf K, Kappl M. Physics and Chemistry of Interfaces. Wiley, Weinheim, Germany. 2013.

(C) 2021 by the author(s). This work is licensed under a Creative Commons Attribution 4.0 International License (http://creativecommons.org/licenses/by/4.0/). Authors retain copyright of their work, with first publication rights granted to Tech Reviews Ltd. 